Egyptian Journal of Aquatic Biology \& Fisheries

Zoology Department, Faculty of Science,

Ain Shams University, Cairo, Egypt.

ISSN $1110-6131$

Vol. 25(1): 555 - 570 (2021)

www.ejabf.journals.ekb.eg

\title{
Removal of cadmium from aqueous solution using modified magnetic glycine modified cross-linked chitosan resin
}

\author{
Nahla M. Mohamed ${ }^{1, *}$, Asmaa S. Hamouda ${ }^{1, *}$, Sayed Abdel Kader ${ }^{1}$, M. Y. El Kady², \\ Mostafa M. H. Khalil ${ }^{2}$ \\ 1. Faculty of Postgraduate studies of Advanced Sciences (PSAS), Beni-Suef University, Beni- \\ Suef, Egypt \\ 2. Chemistry Department, Faculty of Science, Ain Shams University, Cairo, Egypt \\ "Corresponding Author: nahla200030@hotmail.com, asmaa_hamouda@psas.bsu.edu.eg
}

\section{ARTICLE INFO}

\section{Article History:}

Received: Jan. 5, 2021

Accepted: Jan. 24, 2021

Online: Feb. 7, 2021

Keywords:

Magnetic modified

Cadmium removal,

magnetite,

chitosan,

adsorption isotherm

\section{ABSTRACT}

In the present study, the adsorption of $\mathrm{Cd}(\mathrm{II})$ ions onto magnetic glycine modified crosslinked chitosan (MGMCR) resin has been investigated. Batch experiments were performed to study the effect of some parameters such as the initial $\mathrm{Cd}(\mathrm{II})$ concentration, $\mathrm{pH}$ value of the solution, adsorbent dose and the contact time on the adsorption process. The optimal $\mathrm{pH}$ for the adsorption of $\mathrm{Cd}(\mathrm{II})$ was found to be at 5 and the equilibrium was accomplished within 120 minutes. The result obtained from equilibrium adsorption studies are fitted in Langmuir and Freundlich adsorption models and the data was found to agree well with the Langmuir model. The maximum uptake was found to be $172 \mathrm{mg} \mathrm{g}^{-1}$ at $25^{0} \mathrm{C}$ at $\mathrm{pH} 5$.

\section{INTRODUCTION}

Water is the most vital substance for life on the earth and a precious resource for human civilization for many critical areas such as: food, energy, industrial, and the environment. Water resources are increasingly decreasing and need to be preserved. In recent years, industrialization, agricultural activities, rapid population growth and urbanization have contributed negatively to clean water resources (Ali et al., 2018; Basheer, 2018). Different pollutants such as pharmaceuticals, pesticides, dyes and heavy metals have contaminated the water resources. Presence of these contaminants in aqueous environments is environmentally hazardous for human beings and animals. Among these pollutants, heavy metal is one of the most hazardous species, due to their toxic nature especially when their concentrations exceed the allowable limits in the ecosystem. These pollutants are non-biodegradable and can be absorbed by marine life. Once high concentrations of heavy metals enter the food chain, they tend to accumulate in living tissues and thus, dysfunction the system of the human bodies $(\mathbf{F u}, \mathbf{2 0 1 1})$. 
Different treatment methods have been developed to remove heavy metals, which include chemical precipitation, solvent extraction, ion exchange, evaporation, reverse osmosis, electrolysis and adsorption. However, most of these methods tend to show some economical and technical disadvantages (Mehdinia et al,. 2015). For example, chemical precipitation has been widely used to remove dyes or heavy metals from inorganic effluent by increasing the $\mathrm{pH}$ of the solution to convert the soluble substances into an insoluble form (Mehdinia et al., 2015). Even the process is simple, it generates a large quantity of sludge which requires further treatment and high cost.

Adsorption using low-cost natural adsorbents such as agricultural wastes, clay materials and seafood processing wastes is one of the few promising alternatives which can be applied to wastewaters with low concentrations of heavy metal ions (Juang and Shao, 2002).

Chitosan (CS) is well established as an excellent natural adsorbent biopolymer it is efficient, inexpensive, biodegradable, nontoxic, and environmentally friendly (Ngah $\boldsymbol{e t}$ al, 2011, Nguyen et al., 2013). CS molecules contain a substantial number of reactive hydroxyl $(-\mathrm{OH})$ and amino $\left(-\mathrm{NH}_{2}\right)$ groups that can coordinate to toxic pollutants to form complexes with various heavy metal ions. However, the disadvantage of this sorbent when used directly as an adsorbent is its weak acid resistance (i.e., quite soluble in acidic solutions), prone to swelling, weak mechanical stability and small adsorption capacity for certain metal ions (Kuang et al., 2013; Mi $\boldsymbol{e t a l .}$, 2015). To enhance its stability under acidic conditions, cross-linking and solid particle coupling treatments for CS are commonly employed (Hu et al., 2011). The crosslinking procedure may be performed by reaction of chitosan with different reagent such as epichlorhydrin $(\mathrm{ECH})$ (Chen et al., 2008) and glutaraldehyde (Zhang $\boldsymbol{e} \boldsymbol{t} \boldsymbol{a} \boldsymbol{l}$., 2011). Though cross-linking reduces the adsorption capacity, but it will increase the stability of the polymer.

Magnetic modified chitosan resins represent an important class of promising adsorbents as they are highly selective, efficient and easily regenerable relative to other types of adsorbent (Monier et al., 2010; Elwakeel, 2009). These magnetic resins is easily collected from aqueous media using an external magnetic field and displayed higher uptake capacity compared to the magnetic particles-free resin. However, since Chang and Chen reported the CMCS-MNP sorbent in 2005 (Chang and Chen, 2005), many magnetic chitosan has employed for different functions as theranostic applications (Baktask et al., 2020; Lian et al., 2020) and some studies (Kuang et al., 2013; Mi et al., 2015; Song et al., 2016, Nuryono et al., 2020) have focused on its sorption of heavy metals from aqueous solutions.

Cadmium pollution of the environment has become a serious problem due to the increasing consumption of cadmium by industry in the past 20 years. Cadmium is introduced into the environment from the effluence of electroplating industry, and in solid and aqueous discharges from mining operations. Cd(II) toxicity usually occurs through 
oral intake and inhalation (Nogami et al., 2000), affecting organs of the body, such as the liver, kidney, central nervous system, immune system, and blood (Bernard and Lauwerys, 1984).

In this study, we attempted to use the magnetite-crosslinked glycine modified chitosan (MCGC) biopolymer for the adsorption of cadmium ions in aqueous solution. The important physicalchemical properties of MCGC were characterized. A series of adsorption experiments were performed. The $\mathrm{pH}$ influence, kinetics and equilibrium of the cadmium ions onto MCGC beads were studied and some important adsorption parameters have been obtained.

\section{MATERIALS AND METHODS}

\subsection{Materials}

Chitosan (from crab shell), glycine, glutaraldehyde, isopropyl alcohol, epichlorohydren, cadmium acetate dihydrate were Aldrich products. All other chemicals were Prolabo products and were used as received.

\subsection{Preparation of magnetic glycine modified chitosan resin}

\subsubsection{Preparation of magnetite}

Magnetite was prepared using the following method (El Ghandoor et al., 2012). A 250 $\mathrm{mL}(0.4 \mathrm{M})$ of $\mathrm{FeCl}_{3} \cdot 6 \mathrm{H}_{2} \mathrm{O}$ solution was added with stirring to a freshly prepared $250 \mathrm{~mL}$ $(0.2 \mathrm{M})$ of $\mathrm{Fe}$ (II) solution. This mixture is added to the boiling solution of $500 \mathrm{NaOH}(0.5$ $\mathrm{M})$ within 10 second under constant stirring. A black precipitate was formed and was allowed to crystallize for $30 \mathrm{~min}$ with stirring. The precipitate was washed with deoxygenated water (water was boiled to repeal any gases then bubbled with nitrogen gas) under magnetic decantation until the acidity of suspension became below pH 7.5. The precipitate was dried at room temperature to give a dry black powder.

\subsubsection{Synthesis of magnetite chitosan}

The glutaraldehyde-crosslinked chitosan glycine type was prepared as in literature (Khalil et al., 2013). Briefly, three grams of chitosan was dissolved in $20 \%$ aqueous solution of acetic acid and stirred until the solution became homogenous. Then $1 \mathrm{~mL}$ of glutaraldehyde solution (50\%) was added and the solution was stirred with heating for two hours. The $\mathrm{pH}$ of the solution was raised to 6 with $1 \mathrm{M} \mathrm{NaOH}$ and the obtained gel was washed with distilled water several times and kept to dry. The cross-linked chitosan gel obtained in the previous step was suspended in $70 \mathrm{~mL}$ isopropyl alcohol. Then $7 \mathrm{~mL}$ epichlorohydrine $(62.5 \mathrm{mmol})$ dissolved in $100 \mathrm{~mL}$ acetone/water mixture $(1: 1 \mathrm{v} / \mathrm{v})$ was added. The above mixture was stirred for $24 \mathrm{~h}$ at $60{ }^{\circ} \mathrm{C}$. The solid product obtained was filtered off and washed several times with water followed by ethanol. The product and 
glycine $(10 \mathrm{~g})$ were suspended in dioxane $(100 \mathrm{ml})$, then $40 \mathrm{ml} \mathrm{NaOH}(1 \mathrm{M})$ was added and the mixture was refluxed for $3 \mathrm{~h}$. The final product was filtered and washed 3 times with ethanol and with deionized water. The obtained cross-linked chitosan gel from the previous step was suspended in water and the powdered $\mathrm{Fe}_{3} \mathrm{O}_{4}$ was added in 1:2 ratio (chitosan-gly : magnetite). The mixture was refluxed for $6 \mathrm{~h}$ on water bath at $75-80^{\circ} \mathrm{C}$ with continuous stirring. A grayish precipitate was formed, filtered off and washed with deionized water and kept to dry at $60{ }^{0} \mathrm{C}$ for $24 \mathrm{~h}$. The schematic structure of the magnetic glycine-modified chitosan resin is shown in Scheme 1.
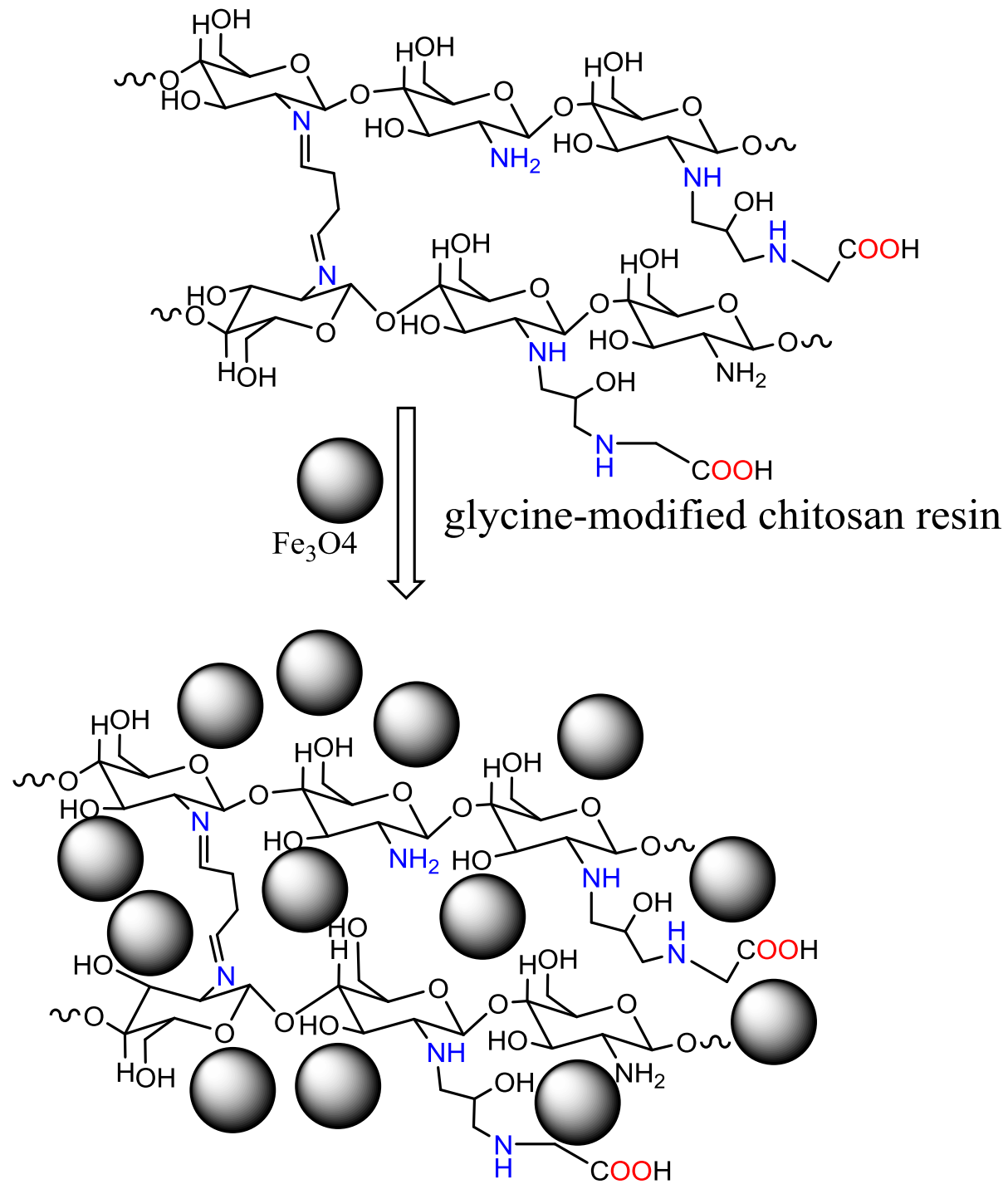

magnetic glycine-modified chitosan resin

Scheme 1 synthesis of magnetic glycine-modified chitosan resin (MGMCR) 


\subsection{Uptake experiments using batch method}

\subsubsection{Preparation of solutions}

Stock solution (1000 ppm) of cadmium was prepared by dissolving $2.317 \mathrm{~g}$ cadmium acetate dihydrate in 1L bi-distilled water. All batch experiments were carried out with adsorbent samples in a $250 \mathrm{~mL}$ conical flasks with $100 \mathrm{~mL} \mathrm{Cd}$ (II) aqueous solutions on a rotary shaker at $200 \mathrm{rpm}$. The concentration of $\mathrm{Cd}(\mathrm{II})$ ions was determined using atomic absorption spectroscopy.

\subsubsection{Effect of $\mathbf{p H}$}

The uptake of $\mathrm{Cd}$ (II) by MGMCR was studied at different $\mathrm{pH}$ values from 2 to 7. The $\mathrm{pH}$ was adjusted using $\mathrm{HCl}$ or $\mathrm{NaOH}$. $0.1 \mathrm{~g}$ of investigated resin was placed in a series of flasks. To each flask $100 \mathrm{~mL}$ of Cd (II) solution (100 ppm) was added. The contents of each flask were shaken for $120 \mathrm{~min}$ on a shaker at $200 \mathrm{rpm}$ at $25 \pm 1{ }^{\circ} \mathrm{C}$ and desired $\mathrm{pH}$. The resin was separated from the solution by filtration. Then the residual concentration of Cd (II ) was determined.

\subsubsection{Effect of contact time}

The effect of contact time is carried out by agitate the adsorption system in temperature controlled incubation shaker for different time intervals (20 to $180 \mathrm{~min}$ ) at an optimum condition (initial metal ion concentration $=200 \mathrm{mg} / \mathrm{l}$, solution $\mathrm{pH}=5.0, \mathrm{MGMCR}$ dose $=$ $0.1 \mathrm{~g}$, temperature $=25^{\circ} \mathrm{C}$ and volume of sample $=100 \mathrm{ml}$ for $\mathrm{Cd}(\mathrm{II})$ ions solution. After the predetermined time interval, the concentration of the ions in the solution (supernatant) was analyzed by using atomic absorption spectroscopy (AAS). The amount of Cd(II) ion adsorbed onto MGMCR at different contact time was calculated by using the following equation:

$q t=(C o-C t) V / m$

where $q t$ is the amount of $\mathrm{Cd}(\mathrm{II})$ ion adsorbed onto MGMCR at any time $t(\mathrm{mg} / \mathrm{g}), C t$ is the final concentration of $\mathrm{Cd}(\mathrm{II})$ ion in the solution at time $t(\mathrm{mg} / \mathrm{l}), V$ is the volume of $\mathrm{Cd}(\mathrm{II})$ ions solution (L), $\mathrm{m}$ is the mass of the MGMCR $(\mathrm{g})$.

\subsubsection{Adsorption isotherms}

Complete adsorption isotherms were carried out by placing $0.1 \mathrm{~g}$ portions of dried resin in a series of flasks containing $100 \mathrm{~mL}$ of $\mathrm{Cd}$ (II) ions at $\mathrm{pH} 5$.. The residual concentration of $\mathrm{Cd}$ (II) was determined. The percentage removal of $\mathrm{Cd}(\mathrm{II})$ ion from the solution can be calculated by using the following formula:

$\%$ Removal $=\frac{\left(C_{0}-C_{e}\right)}{C_{0}} \times 100$ 


\section{RESULTS AND DISCUSSION}

3.1 Characterization of the adsorbent magnetic glycine-modified chitosan resin (MGMCR)

The XRD pattern of the final powders is show in Figure 1. The XRD spectrum exhibited peaks corresponding to $\mathrm{Fe}_{3} \mathrm{O}_{4}$, marked with their indices (220) at $2 \theta=32.5^{\circ}$, (311) at 2 $\theta=35.4^{0},(400)$ at $2 \theta=43.4^{0},(422)$ at $2 \theta=53.9^{0},(511)$ at $2 \theta=57.2^{0}$ and (440) at $2 \theta=$ $62.4^{0}$, which is similar to that reported before for $\mathrm{Fe} 3 \mathrm{O} 4$ nanoparticles (El Ghandoor $\boldsymbol{e t}$ al., 2012; Liao and Chen, 2001) indicating that the $\mathrm{Fe}_{3} \mathrm{O}_{4} \mathrm{NPs}$ is well crystalline.

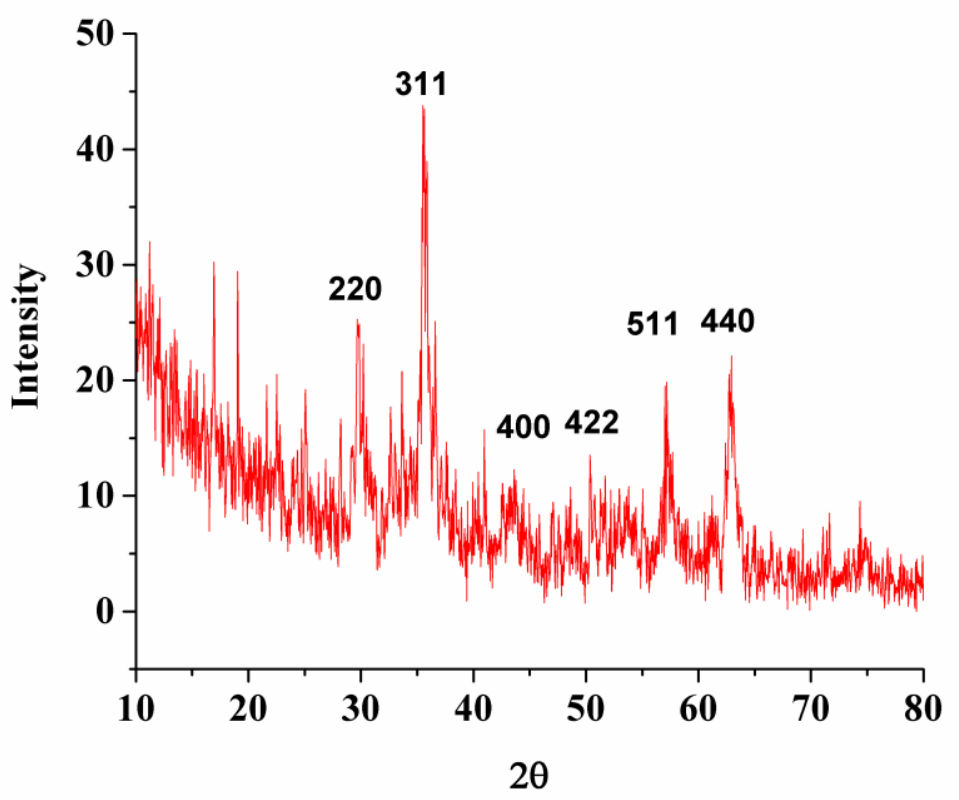

Fig. 1. The X-ray diffraction pattern of Fe3O4 nanoparticles in MGMCR Resin

TEM micrograph of the colloidal dispersions of MGMCR was obtained by a transmission electron microscope and the typical TEM micrograph for the chitosan-bound $\mathrm{Fe}_{3} \mathrm{O}_{4}$ nanoparticles is shown in Fig. 2. It is clear that the chitosan can inhibit the aggregation of nanoparticles because of the steric repulsion. So, chitosan-bound $\mathrm{Fe}_{3} \mathrm{O}_{4}$ nanoparticles had essentially mean diameter of about $25 \mathrm{~nm}$ as the nanopartcle size of non-bound $\mathrm{Fe}_{3} \mathrm{O}_{4}$. 


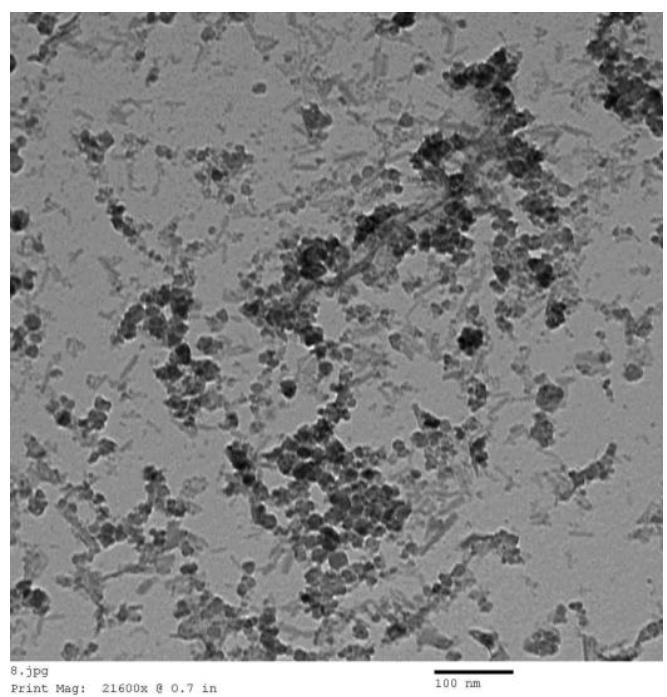

Fig. 2 TEM micrograph showing the size and distribution of Fe3O4 nanoparticles in MGMCR

\section{FTIR}

The FTIR spectra $\left(400-4000 \mathrm{~cm}^{-1}\right)$ of the chitosan, glycine-modified chitosan and magnetic glycine-modified chitosan resin are shown in Figure 3. Usually, the major peaks of the chitosan, Fig. 3a, are located at $3420 \mathrm{~cm}^{-1}$ that attributed to O-H and N-H stretching vibrations and the peak at $2882.9 \mathrm{~cm}^{-1}$ due to $-\mathrm{CH}$ stretching vibration in $-\mathrm{CH}$, and $-\mathrm{CH}_{2}$ and the stretching vibration at $1650 \mathrm{~cm}^{-1}$ for $\mathrm{NH}$ stretching bending vibration. The band observed at $1320 \mathrm{~cm}^{-1}$ is assigned to $\mathrm{C}-\mathrm{N}$ bending (Li and Bai, 2005). Also, the IR spectrum for chitosan has a sharp peak at $1420 \mathrm{~cm}^{-1}$, which is caused by the presences of the primary amine group, $\mathrm{NH}_{2}$. Meanwhile, based on the spectrum of glycine-modified chitosan beads, there is a significant new peak at $1659 \mathrm{~cm}^{-1}$, which can be attributed to an imine bond (C=N), Fig. 3.b. The new bands at $1500 \mathrm{~cm}^{-1}$ and at 1424 $\mathrm{cm}^{-1}$ can be assigned to $\mathrm{COO}^{-}$(stretching vibrations from glycine). The IR spectrum of magnetic crosslinked chitosan glycine exhibited bands similar to the glycine-modified chitosan with respective shift (Fig. 3c). Strong peak at $573 \mathrm{~cm}^{-1}$ ( $\mathrm{Fe}-\mathrm{O}$ vibration of $\mathrm{Fe}_{3} \mathrm{O}_{4}$ ) indicated presence of $\mathrm{Fe}_{3} \mathrm{O}_{4}$ nanoparticles in MGMCC material (Yuwei and Jianlong, 2011). 


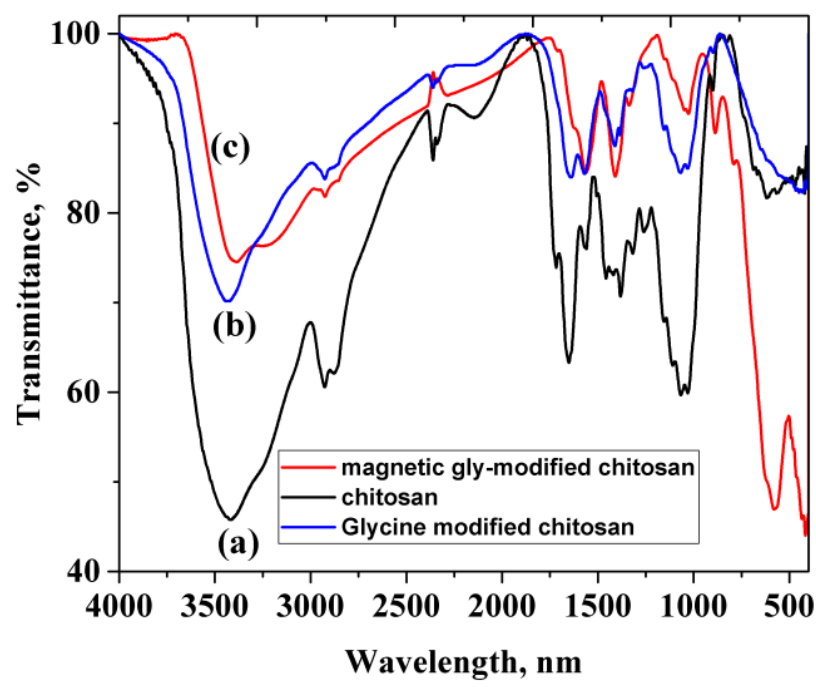

Fig. 3. FTIR spectra of (a) chitosan (b) glycine modified chitosan, and (c) magnetic modified chitosanbound $\mathrm{Fe}_{3} \mathrm{O}_{4}$ nanoparticles.

\section{Thermal Analysis}

The overall thermogravimetric decomposition process of chitosan, glycine modified chitosan derivative and its magnetic modified chitosan-bound $\mathrm{Fe}_{3} \mathrm{O}_{4}$ nanoparticles under nitrogen is presented in Fig. 4. TG curve of chitosan is a smooth curve with only two weight-loss steps, which are well explained in the literature (Mucha and Pawlak, 2005; Ziegler-Borowska et al. 2016). The first step, occurring at lower temperatures (20-120 ${ }^{0} \mathrm{C}$ ), is assigned to releasing of adsorbed water, which is obvious because of the CS hydrophilicity. The main destruction of chitosan biopolymer takes place in the second stage in the temperature range of $200-500{ }^{\circ} \mathrm{C}$ indicating that the thermal degradation of chitosan in nitrogen atmosphere is simple and is a one-step reaction after dehydration. It was repeatedly confirmed that the main chain split, abstraction of side groups and ring opening reactions occur in this step. The carbonaceous residue in $\mathrm{N}_{2}$ atmosphere is about $35 \%$ at $800{ }^{\circ} \mathrm{C}$ (but even at $1000{ }^{\circ} \mathrm{C}$ the decay is not completed). 


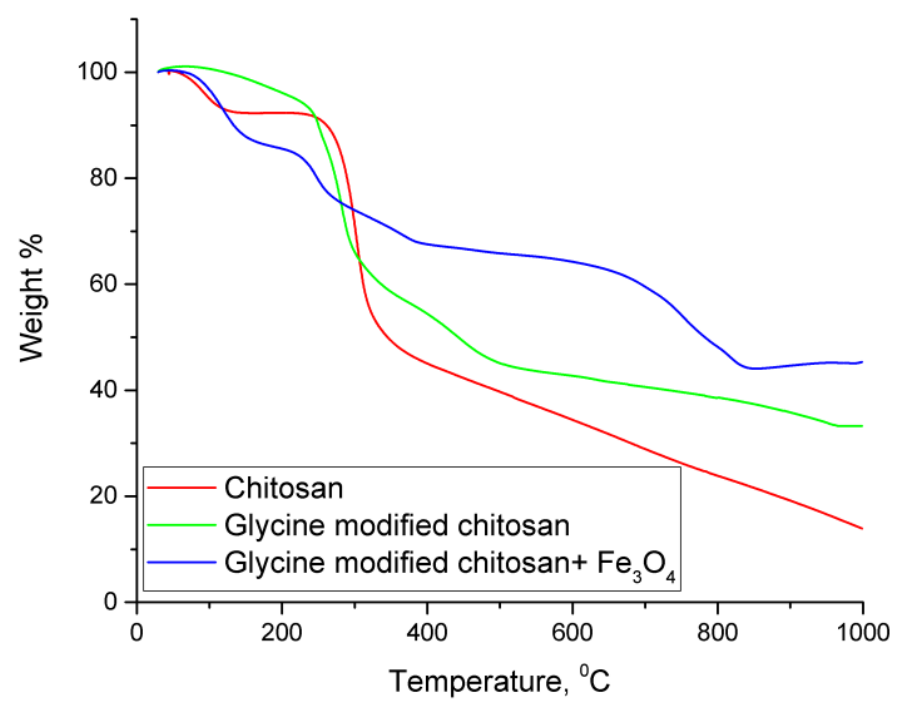

Fig. 4. Thermogravimetric curves of chitosan, glycine modified chitosan and magnetic glycin modified chitosan.

Thermogravimetric curves of modified chitosan exhibit three steps in the studied temperature range. The first two steps are overlapped and start at room temperature and proceeds to about $368{ }^{\circ} \mathrm{C}$, represent about $40 \%$ due to decomposition of chitosan and the second step extends to around $495{ }^{\circ} \mathrm{C}$ with weight loss of $13.16 \%$. Finally, at higher temperatures $\left(>500{ }^{\circ} \mathrm{C}\right)$ the decomposition is continued and systematic mass loss without any maximum rate is observed giving residue of $35 \%$.. Thermogravimetric profiles of MGMCR vary from the chitosan and chitosan derivative. TG curves of MGMCR with $\mathrm{Fe}_{3} \mathrm{O}_{4}$ (Fig. 4) show four steps of thermal degradation. The first step starts at from 32 to $187{ }^{\circ} \mathrm{C}$ with weight loss of $14.2 \%$ due to water desorption. The other three steps continue degradation with remaining weight percent of $44.29 \%$ which is higher than chitosan or modified chitosan. The meaningful difference is caused by high residue at the end of experiment due to the inorganic part presence. The last step of MGMCR thermal decomposition, occurring above $600{ }^{\circ} \mathrm{C}$, can be assigned to changes in the inorganic core.

Investigation of the removal ability of the magnetite glycine modified chitosan resin in aqueous media

Removal study of cadmium using magnetite glycine modified chitosan bound $\mathrm{Fe}_{3} \mathrm{O}_{4}$ nanoparticles MGMCR is carried out at optimal experimental conditions. Then, first, the removal efficiency was optimized by changing the experimental factors one at a time.

Effect of $\mathrm{pH}$

The adsorption of the solutions containing $\mathrm{Cd}$ (II) ions (100 ppm) by the chitosan-bound $\mathrm{Fe}_{3} \mathrm{O}_{4}$ nanoparticles (as a magnetic nano-adsorbent) was investigated in aqueous solutions for $\mathrm{pH}$ range $2-7$, Fig. 5, at room temperature. The removal efficiency of $\mathrm{Cd}$ (II) 
increased with increasing $\mathrm{pH}$ to a maximum value at $\mathrm{pH} 5$ and then declined. This can be explained with the fact that, in the strong acid solution more protons will be more available to protonate the nitrogen of chitosan and amino acid groups reducing the binding sites for $\mathrm{Cd}(\mathrm{II})$ ions. With the increase of $\mathrm{pH}$, the amino groups become free from protanation due to a decrease in the concentration of hydrogen ions leading to the decrease in competition of $\mathrm{H}^{+}$with metal ions for sorption sites and thus the adsorption capacity increases. $\mathrm{Cd}^{2+}$ ions, which is the main hydrolyzed cadmium species in the $\mathrm{pH}$ range 5.0-7.0 appears in the form of $\mathrm{Cd}(\mathrm{OH})^{+}, \mathrm{Cd}(\mathrm{OH})_{2}$, and $\mathrm{Cd}(\mathrm{OH})_{3}{ }^{-}$. The fraction of negatively charged hydrolysis products in the solution increases as $\mathrm{pH}$ increases (Madala et al., 2017). Therefore, $\mathrm{pH} 5$ was selected as optimum condition for adsorption of $\mathrm{Cd}(\mathrm{II})$ on $\mathrm{MC}$

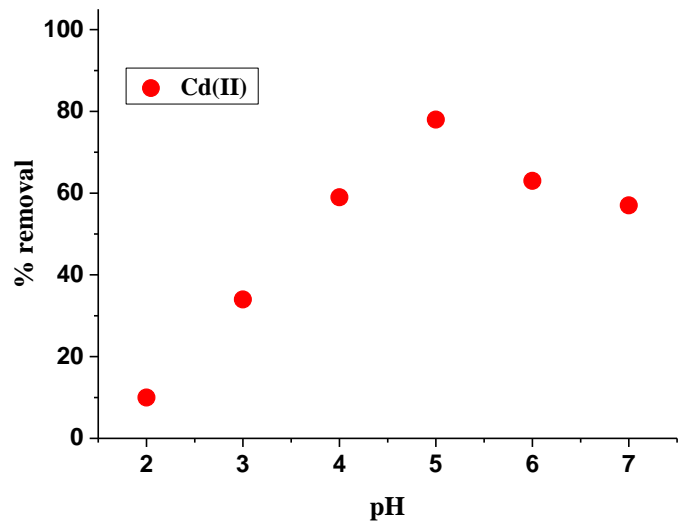

Fig. 5. Effect of $\mathrm{pH}$ on percent removal of $\mathrm{Cd}(\mathrm{II})$ onto MGMCC. (Experimental conditions: initial conc. $100 \mathrm{mg} / \mathrm{L}$, contact time $2 \mathrm{~h}$, adsorbent dose $0.1 \mathrm{~g}$, time: $120 \mathrm{~min}, 200 \mathrm{rpm}$ and temperature $25^{\circ} \mathrm{C}$ ).

\subsection{Effect of adsorbent dosage}

The experiments on the effect of amount of adsorbent on adsorption of $\mathrm{Cd}$ (II) were performed at $\mathrm{pH} 5.0$ with $100 \mathrm{ml}$ of adsorbate solution by varying the amount of adsorbent from 0.05 to $0.2 \mathrm{~g}$. The percent removal of $\mathrm{Cd}(\mathrm{II})$ ions increases with increase of amount of MGMCC due to the greater availability of active binding sites of the modified chitosan. The maximum removal efficiency is with $0.1 \mathrm{~g}$ of MGMCC and the maximum percent removal is about $82 \%$ (Fig. 6). 


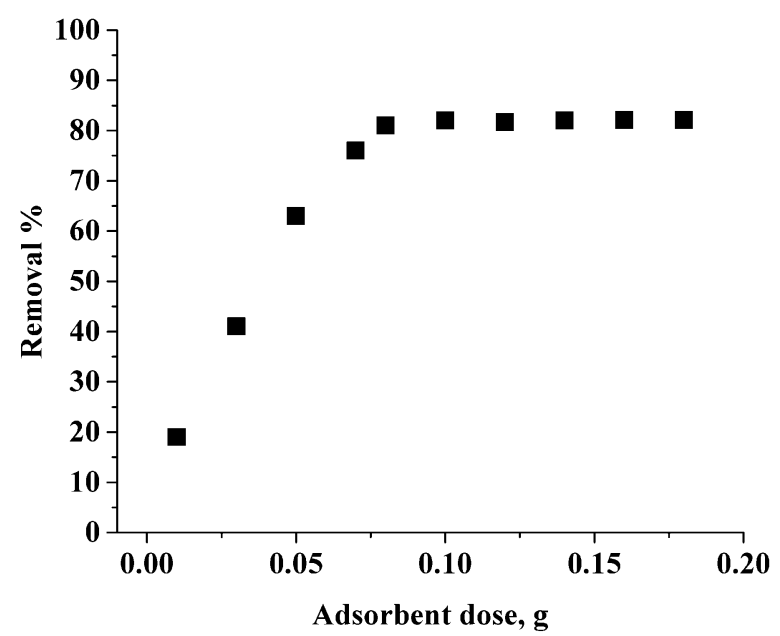

Fig. 6. Effect of adsorbent dose on percent removal of Cd(II) onto MGMCC. (Experimental conditions: initial conc. $100 \mathrm{mg} / \mathrm{L}$, contact time $2 \mathrm{~h}, \mathrm{pH} 5.0,150 \mathrm{rpm})$.

\subsection{Adsorption kinetics}

The effect of contact time on the removal of Cd (II) ions by the MGMCC has been investigated over the range from 10 to $180 \mathrm{~min}$ with initial concentrations of 50, and the results are shown in Figure 7. The contact time curves show rapid adsorption rate of $\mathrm{Cd}$ (II) ions is increased. After that, uptake rate slowly declines with lapse of time and tends to be equilibrium at $2 \mathrm{~h}$. It can be explained that there were plenty of available adsorption sites. With the adsorption process proceeding, the adsorption sites were occupied gradually and the percent removal elevated slowly and the adsorption reaches its equilibrium in $2 \mathrm{~h}$. Therefore, the optimum contact time for adsorption of $\mathrm{Cd}$ (II) is about $120 \mathrm{~min}$.

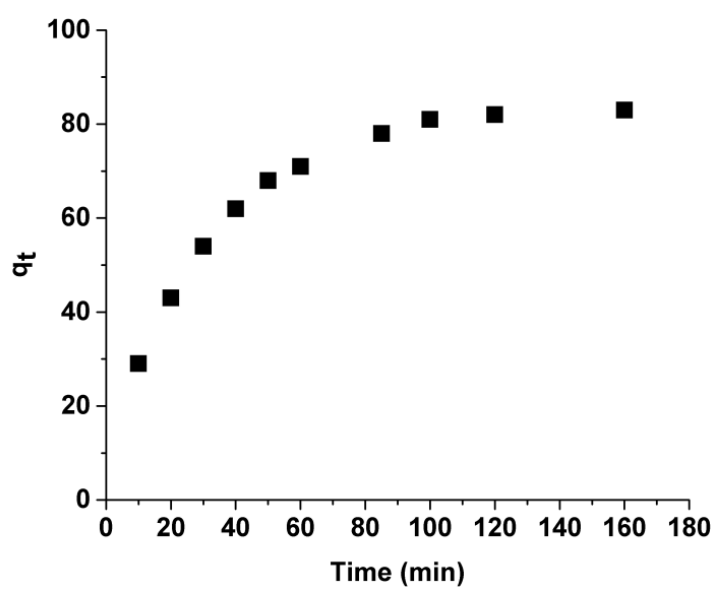

Fig. 7. Effect of contact time on adsorption of Cd(II) (initial concentration $200 \mathrm{mg} \mathrm{L}^{-1}$, MGMCC, $2 \mathrm{~g} / \mathrm{L}$, $\mathrm{pH}$ 5.0, shaking rate $150 \mathrm{rpm}, 30^{\circ} \mathrm{C}$ ). 


\subsection{Adsorption isotherm}

Adsorption isotherm studies are performed to reflect the performance of adsorbents in adsorption processes. Many isotherms are well-known (Wang and Guo, 2020) and in this study, Langmuir and Freundlich are used to determine the adsorption equilibrium between the adsorbent and the metal ion. The Langmuir isotherm model assumes that a monomolecular layer is formed when adsorption takes place without any interaction between the adsorbed molecules. The Langmuir model can be represented as:

$$
\frac{\mathrm{C}_{\mathrm{e}}}{\mathrm{q}_{\mathrm{e}}}=\frac{\mathrm{C}_{\mathrm{e}}}{\mathrm{Q}_{\max }}+\frac{1}{K_{L} \mathrm{Q}_{\max }}
$$

where qe the adsorbed value of $\mathrm{Cd}(\mathrm{II})$ ions at equilibrium concentration $(\mathrm{mg} / \mathrm{g}), \mathrm{Q}_{\max }$ is the maximum adsorption capacity $(\mathrm{mg} / \mathrm{g})$ and $\mathrm{K}_{\mathrm{L}}$ is the Langmuir binding constant which is related to the energy of adsorption $\left(\mathrm{L} \mathrm{mg}^{-1}\right), \mathrm{C}_{\mathrm{e}}$ is the equilibrium concentration of $\mathrm{Cd}(\mathrm{II})$ in solution $(\mathrm{mg} / \mathrm{L})$.

The experimental data were plotted as Ce/qe versus $\mathrm{Ce}$ in order to evaluate the values of Langmuir constants $\mathrm{q}_{\mathrm{m}}$ and $\mathrm{K}_{\mathrm{L}}$. The important characteristics of the Langmuir isotherm can be expressed in terms of a dimensionless constant separation factor $R_{L}$ that is given by

$$
R_{L}=\frac{1}{1+K_{\mathrm{L}} \mathrm{C}_{\mathrm{i}}}
$$

where $C i\left(\mathrm{mg} \mathrm{g}^{-1}\right)$ is the highest initial concentration of adsorbate and $R_{L}$ values $0<R_{L}<$ 1 imply favorable adsorption, unfavourable when $R L>1$, and irreversible when $R L=0$.. The Freundlich isotherm model is an empirical equation assuming that the adsorption process takes place on heterogeneous surfaces and adsorption capacity is related to the concentration of metal ion at equilibrium. This isotherm model is defined by the equation (Ayawei et al., 2017) below:

$$
\log q_{e}=\log K_{F}+\frac{1}{n} \log C_{e}
$$

where The values of $K$ and $1 / n$, which roughly correspond to the adsorption capacity and the heterogeneity factor, respectively.

Isotherm parameters for the Langmuir and Freundlich models for the (GMCCR) are presented in Table 1 . At $25^{\circ} \mathrm{C}$ the maximum uptakes for (GMCCR) are $172 \mathrm{mg} / \mathrm{g}$, . The values of $\mathrm{K}_{\mathrm{L}}$ and $\mathrm{Q}_{\max }$ for adsorption of $\mathrm{Cd}$ (II) on resin was calculated from Langmuir isotherm (Fig. 7b). The values of $\mathrm{R}^{2}$ reported in Table 1, which is a measure of the goodness-of-fit, confirm the better representation of the experimental data by Langmuir model. This indicates the homogeneity of active sites on the resin surface and suggest that the adsorption of $\mathrm{Cd}(\mathrm{II})$ occurred mainly by monolayer reaction. 

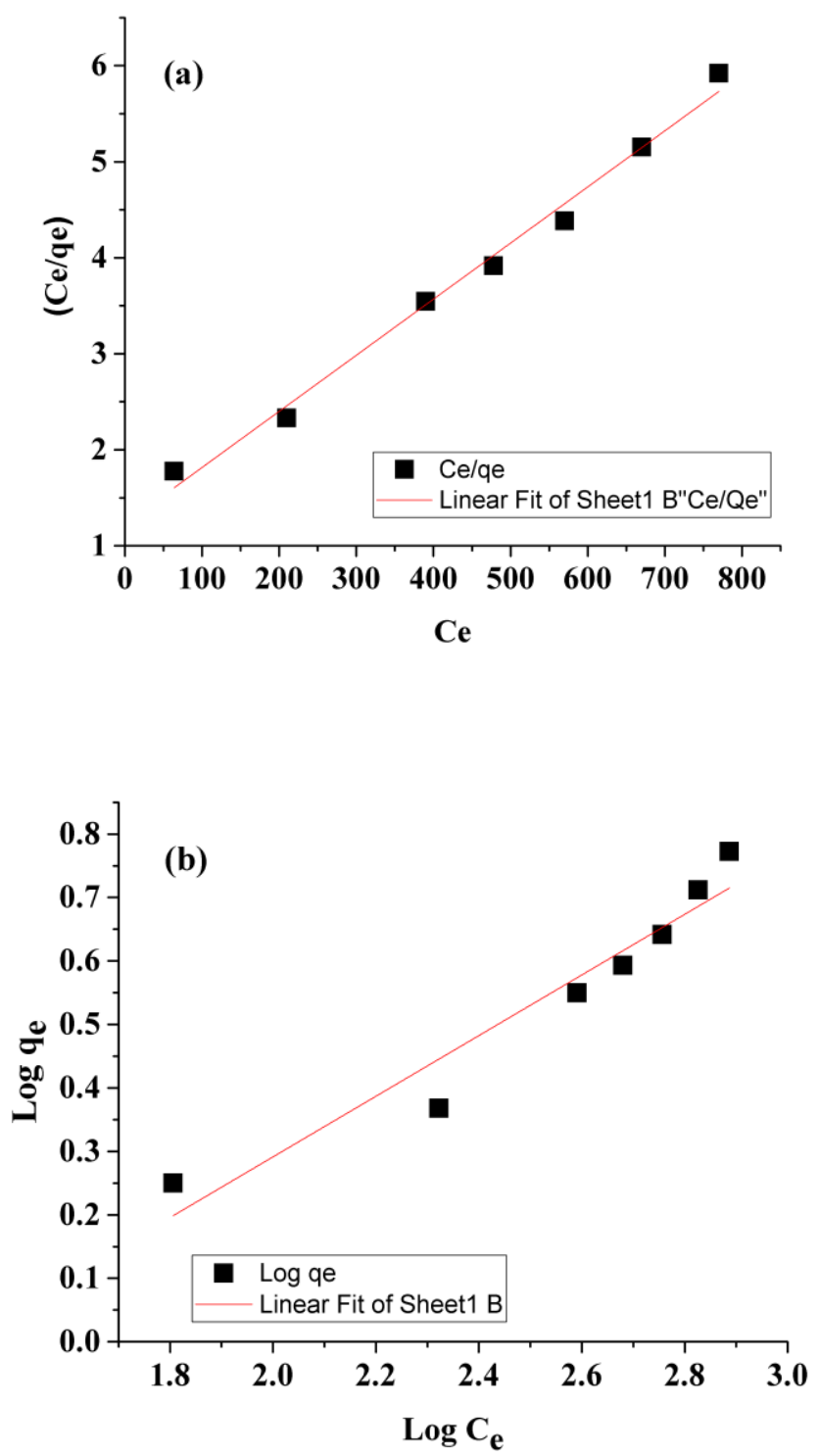

Fig. 8. (a) Langmuir and (b) Freundlich isotherms for the adsorption of Cd(II) on (MGMCR) at room temperature; $\mathrm{pH}$ 5; contact time 120 min.

Table 1 Isotherms constants for adsorption of Cd (II) on magnetic Chitosan-Glycine resin

\begin{tabular}{ccccccc}
\hline \multirow{2}{*}{$\begin{array}{c}\text { Lemp. } \\
(\mathrm{K})\end{array}$} & \begin{tabular}{c}
$\mathrm{Q}$ Langmuir constants \\
\cline { 2 - 6 }
\end{tabular} & $\begin{array}{c}\mathrm{K}_{\mathrm{L}} \\
(\mathrm{mg} / \mathrm{g})\end{array}$ & $\left.\mathrm{L} \mathrm{mg}^{-1}\right)$ & $1 / \mathrm{n}$ & $\mathrm{K}_{\mathrm{f}}$ & $\mathrm{R}^{2}$ \\
\hline 298 & 172.41 & 0.1912 & 0.990 & 0.4778 & 0.216 & 0.933 \\
\hline
\end{tabular}




\section{CONCLUSION}

The present study showed that the magnetic modified chetosan prepared with simple preparation method and low cost is a promising green biosorbent that is expected to be applied effectively in treatment of the wastewater effluents from cadmium industry in the future..

\section{REFERENCES}

Ali, I.; Alharbi, O.M.L.; Tkachev, A. ; Galunin, E., Burakov, A. and Grachev, V.A. (2018) Water treatment by new-generation graphene materials: hope for bright future, Environ. Sci. Pollut. R. 25: 7315-7329, https://doi.org/10.1007/s11356-018-1315-9.

Ayawei, N. ; Ebelegi, A. N. and Wankasi, D. (2017) Modelling and Interpretation of Adsorption Isotherms Journal of Chemistry Volume 2017, Article ID 3039817 , https://doi.org/10.1155/2017/3039817

Baktash, M. S.; Zarrabi, A.; Avazverdi, E. and Reis N. M. (2020) Development and optimization of a new hybrid chitosan-grafted graphene oxide/magnetic nanoparticle system for theranostic applications, Journal of Molecular Liquids, https://doi.org/10.1016/i.molliq.2020.114515

Basheer A.A. (2018) New generation nano-adsorbents for the removal of emerging contaminants in water, J. Mol. Liq. 261: 583-593.

Bernard A. and Lauwerys R. (1984) Cadmium in human population. (Cadmium: a complex environmental problem, Part II), Experientia 40, 143-152.

Bindu, V.U. and Mohanan P.V. (2020) Thermal deactivation of $\alpha$-amylase immobilized magnetic chitosan and its modified forms: A kinetic and thermodynamic study Carbohydrate Research, (In Press) https://doi.org/10.1016/j.carres.2020.108185.

Chang, Y-C and Chen, D-H (2005) Preparation and adsorption properties of monodisperse chitosan-bound $\mathrm{Fe}_{3} \mathrm{O}_{4}$ magnetic nanoparticles for removal of $\mathrm{Cu}$ (II) ions. J Colloid Interface Sci 283:446-45.

Chen, A.H. ; Liu, S.C. ; Chen, C.Y. and Chen, C.Y. (2008) Comparative adsorption of $\mathrm{Cu}(\mathrm{II}), \mathrm{Zn}(\mathrm{II})$, and $\mathrm{Pb}$ (II) ions in aqueous solution on the crosslinked chitosan with epichlorohydrin J. Hazard. Mater. 154(1-3):184-191.

El Ghandoor, H.; M. Zidan, H.; Khalil, M.M.H. and Ismail M. I. M. (2012) Synthesis and Some Physical Properties of Magnetite (Fe3O4) Nanoparticles Int. J. Electrochem. Sci., 7: 5734 - 5745.

Elwakeel, K.Z. ; Atia, A.A. and Donia, A.M. (2009) Removal of Mo(VI) as oxoanions from aqueous solutions using chemically modified magnetic chitosan resins, Hydrometallurgy 97: 21-28.

Fu, F. and Wang, Q. (2011). Removal of heavy metal ions from wastewaters: A review. Journal of Environmental Management, 92(3): 407-418. 
Hu, X-J; Wang, J-S; Liu, Y-G, Li, X; Zeng, G-M; Bao, Z-I, Zeng, X-X, Chen, A-W and Long F (2011) Adsorption of chromium (VI) by ethylenediamine-modified crosslinked magnetic chitosan resin: isotherms, kinetics and thermodynamics. J Hazard Mater 185:306-314

Juang, R. S. and Shao, H J. (2002). A simplified equilibrium model for sorption of heavy metal ions from aqueous solutions on chitosan. Water Research, 36: 29993008 .

Khalil, M.M.H.; Al-Wakeel, K. Z.; Abd El Rehim, S. S. and Abd El Monem, H. (2013) Efficient removal of ferric ions from aqueous medium by amine modified chitosan J. Environm. Chem. Engineering 1: 566-573.

Kuang S-P.; Wang Z-Z; Liu J. and Wu Z-C (2013) Preparation of triethylenetetramine grafted magnetic chitosan for adsorption of $\mathrm{Pb}$ (II) ion from aqueous solutions. J Hazard Mater 260:210-219.

Kumar M. and Puri A. (2012), A review of permissible limits of drinking water, Indian J Occup Environ Med. Jan-Apr; 16(1): 40-44.

Lagergren S. (1898) About the theory of so-called adsorption of soluble substances. Kungliga Svenska Vet 24: 1-39.

Li N. and Bai R., (2005) A Novel amine-shielded surface cross-linking of chitosan hydrogel beads for enhanced metal adsorption performance Ind. Eng. Chem. Res. 44: 6692-6700.

Lian, Z.; Li Y.; Xian, H.; Ouyang, X.; Lu, Y.; Peng, X. and Hu, D. (2020) EDTAfunctionalized magnetic chitosan oligosaccharide and carboxymethyl cellulose nanocomposite: Synthesis, characterization, and $\mathrm{Pb}(\mathrm{II})$ adsorption performance International Journal of Biological Macromolecules, Part A, 165: 591-600

Liao, M.H. and Chen, D.H.( 2001) Immobilizing of Yeast Alcohol Dehydrogenase on Magnetic Nanoparticles for Improving its Stability. Biotechnol. Lett., 23, 1723-1727.

Lu, S.; Li, H.; Zhang, F.; Du, N. and Hou, W. (2016) Sorption of Pb(II) on carboxymethyl chitosan-conjugated magnetite nanoparticles: application of sorbent dosage-dependent isotherms, Colloid Polym Sci 294:1369-1379.

Madala, S.; Nadavala, S.K.; Vudagandla, S.; Boddu, V. M. and Abburi, K. (2017) Equilibrium, kinetics and thermodynamics of Cadmium (II) biosorption on to composite chitosan biosorbent Arabian Journal of Chemistry 10: S 1883-S1893

Mehdinia, A.; Shegefti, S. and Shemirani, F. (2015). Removal of lead(II), copper(II) and zinc(II) ions from aqueous solutions using magnetic amine-functionalized mesoporous silica nanocomposites. Journal of the Brazilian Chemical Society, 26(11): 2249-2257. 
Mi, F-L; Wu, S-J. and Chen, Y-C. (2015) Combination of carboxymethyl chitosancoated magnetic nanoparticles and chitosan-citrate complex gel beads as a novel magnetic adsorbent. Carbohydr Polym 131:255-263

Monier, M.; Ayad, D.M.; Wei, Y. and Sarhan, A.A. (2010) Adsorption of Cu(II), $\mathrm{Co}(\mathrm{II})$, and $\mathrm{Ni}(\mathrm{II})$ ions by modified magnetic chitosan chelating resin, J. Hazard. Mater. 177: 962-970.

Mucha, M and Pawlak, A. (2005) Thermal analysis of chitosan and its blends. Thermochim Acta. 427:69-76.

Ngah, W.S.W; Teong, L.C. and Hanafiah, M, (2011) Adsorption of dyes and heavy metal ions by chitosan composites: a review. Carbohydr Polym 83:1446-1456

Nguyen, T.A.H; Ngo, H.H.; Guo, W.S.; Zhang, J.; Liang, S.; Yue, Q.Y.; Li, Q. and Nguyen T.V. (2013) Applicability of agricultural waste and by-products for adsorptive removal of heavy metals from wastewater. Bioresour Technol 148:574585 .

Nogami, E.M.; Kimura, C.C.M.; Rodrigues, C.; Malagutti, A.R.; Lenzi, E. and Nozaki J. (2000), Effects of dietary cadmium and its bioconcentration in tilapia Oreochromis niloticus, Ecotoxicol. Environ. Saf. 45: 291-295.

Nuryono, N.; Miswanda, D.; Sakti, S. C. W.; Rusdiarso, B.; Krisbiantoro, P. A.; Utami, N.; Otomo R. and Kamiya Y. (2020) Chitosan-functionalized natural magnetic particle@silica modified with (3-chloropropyl)trimethoxysilane as a highly stable magnetic adsorbent for gold(III) ion, Materials Chemistry and Physics 255: 123507.

Wang, J. and Guo, X. (2020) Adsorption isotherm models: Classification, physical meaning, application and solving method, Chemosphere, https://doi.org/10.1016/j.chemosphere.2020.127279.

Yuwei, C. and Jianlong, W., (2011) Preparation and characterization of magnetic chitosan nanoparticles and its application for $\mathrm{Cu}(\mathrm{II})$ removal, Chem. Eng. J. 168: 286292.

Zhang, Q.; Deng, S.; Yu, G. and Huang, J. (2011), Removal of perfluorooctane sulfonate from aqueous solution by crosslinked chitosan beads: Sorption kinetics and uptake mechanism Bioresour. Technol 102 (3): 2265-2271.

Ziegler-Borowska, M.; Chełminiak, D.; Kaczmarek, H. and Kaczmarek-Kedziera, A. (2016) Effect of side substituents on thermal stability of the modified chitosan and its nanocomposites with magnetite J Therm Anal Calorim 124:1267-1280 